\title{
V-excision modification for direct necklift
}

Geoffrey G Hallock MD

Division of Plastic Surgery, The Lehigh Valley Hospital, Allentown, Pennsylvania, USA

GG Hallock. V-excision modification for direct necklift. Can J Plast Surg

1995;3(2):83-86. The occasional patient who desires solely aesthetic correction of a neck deformity, but refuses to undergo a classical rhytidectomy, might be a candidate for direct neck skin excision. Eight such patients underwent a V-excision modification with Z-plasty for direct necklift with reasonable results achieved in six (75\%). All complications (25\%) including hypertrophic scarring and vertical neck contracture occurred in females. All scars, however inconspicuous, were still apparent upon close inspection. Appropriate awareness of these sequelae must be acceptable to any candidate before embarking on this unconventional approach to improvement of neck contour.

Key Words: Direct necklift, Facelift, Neck rhytidectomy

\section{Modification de l'excision en $\mathrm{V}$ pour le redrapage cervical}

RÉSUMÉ : Les quelques patients qui ne souhaitent qu'une correction esthétique d'une difformité au niveau cervical et qui refusent de subir une rhytidectomie classique peuvent être de bons candidats pour une excision cutanée directe au niveau du cou. Huit patients de cette catégorie ont subi une excision en $\mathrm{V}$ modifiée, avec plastie en $\mathrm{Z}$ pour redrapage cervical direct avec des résultats satisfaisants chez six d'entre eux ( $75 \%)$. Toutes les complications $(25 \%)$, y compris la cicatrisation hypertrophique et la contracture verticale du cou, sont survenues chez des patientes. Toutes les cicatrices, même discrètes, étaient encore apparentes à l'inspection attentive. Tout candidat à cette approche peu orthodoxe pour l'amélioration du contour du cou doit être au courant des séquelles possibles et les accepter.

Not altogether uncommon is the consultation requested solely with the intent to seek elimination of an excessive vertical fold of skin and fat from the anterior neck region. The obvious surgical solution would be a conventional cervicofacial rhytidectomy. Yet some patients are reluctant to pursue such advice and are insistent that only a local procedure be performed instead.

This concept is not without precedent as references to local dermolipectomies with direct neck skin excisions appear as early as 1932 (1). Cronin and Biggs outlined a technique using a superior transverse ellipse and vertical rectangle skin excision followed by Z-plasty (2); this was subsequently modified to become their method of choice for the male seeking neck improvement but specifically refusing a facelift $(3,4)$. They also provided an historical overview of the development of this concept, beginning with simple transverse or vertical elliptical skin excisions, H-shaped incisions, and ultimately 
incorporation of Z-plasties to prevent vertical shortening (2). Kesselring more recently advocated a long W-plasty extending from the chin to the sternal notch that purported to minimize any apparent scarring (5).

In spite of this prior experience, cosmetic neck enhancement by a direct approach has been paid little attention today because of the superb results usually obtainable from standard rhytidectomy procedures that altogether avoid any conspicuous neck scars (6-8).

Nevertheless, a minor variation of this theme serves to reintroduce this idea lest it be overlooked as an alternative in unusual circumstances.

\section{METHOD}

Examination of the patient must initially be done in an upright position (Figure 1A) to determine accurately the degree of vertical skin redundancy, location of platysmal bands, and site of fatty accumulations. By pinch test, the amount that can be safely excised while still allowing primary skin closure is marked. Since this width usually is greatest just below the submental crease and narrows toward the sternal notch, this forms a triangle of skin based just below the submental crease with an apex near the thryoid cartilage (Figure 1B). The length of the base is extended laterally, but the limbs of the V are incurved slightly in a medial direction to intersect with this horizontal line to insure that the superior closure will form a T-shape without tension.

Following local anaesthesia infiltration, the midline skin as marked is excised, with minimal undermining of the remaining skin flaps. All excessive supraplatysmal or subplatysmal fat can be directly visualized and removed. The platysmal muscles may be plicated or treated according to the surgeon's preference (Figure 1C) $(9,10)$. After meticulous hemostasis, the lateral skin edges are advanced with a subcutaneous closure. One or two Z-plasties are essential, designed such that their central member will ultimately fall into previously marked obvious horizontal neck creases. This manoeuvre minimizes vertical tension often noted during the closure. Skin sutures and minor dressings complete the procedure (Figure 1D).

Over the past decade, only eight patients have requested correction of their neck deformity but refused a conventional facelift (Table 1). Instead, they requested a local dermolipectomy for necklift as described. 


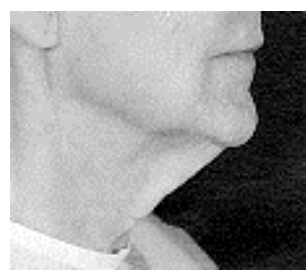

Figure 1A) Lateral view of elderly female desiring correction only of midline neck skin and fat excess

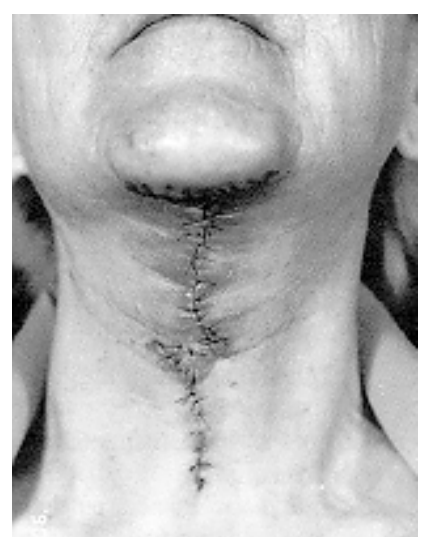

Figure 1D) T-shaped wound closure with single Z-plasty for vertical lengthening

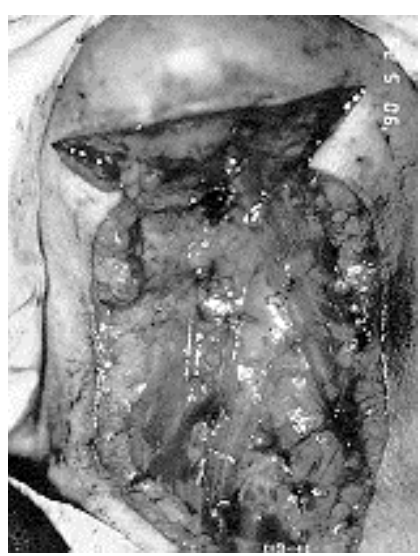

Figure 1B) Immediately after $V$ excision of skin redundancy with medial incurved flaps adjacent to the base incision that paralleled the submental crease, which facilitated closure of the superior portion of the incision and exposure of the anterior platysmal muscle border (arrows)

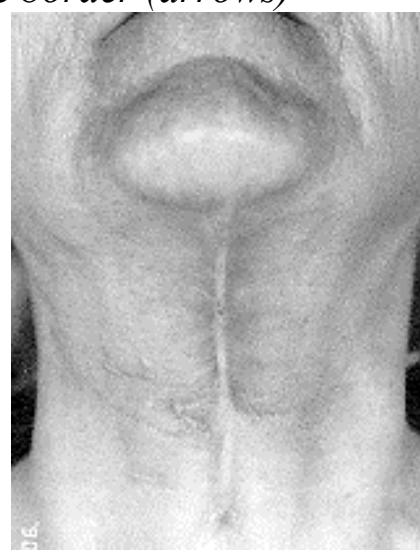

Figure 1E) Vertical contracture band two months postoperative

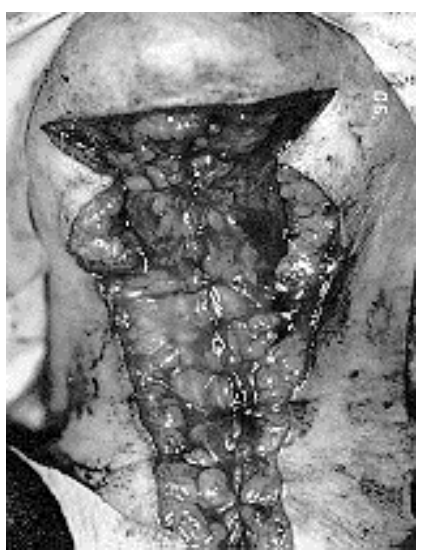

Figure 1C) Subplatysmal and supraplatysmal lipectomy completed with platysmal pliation (arrows)

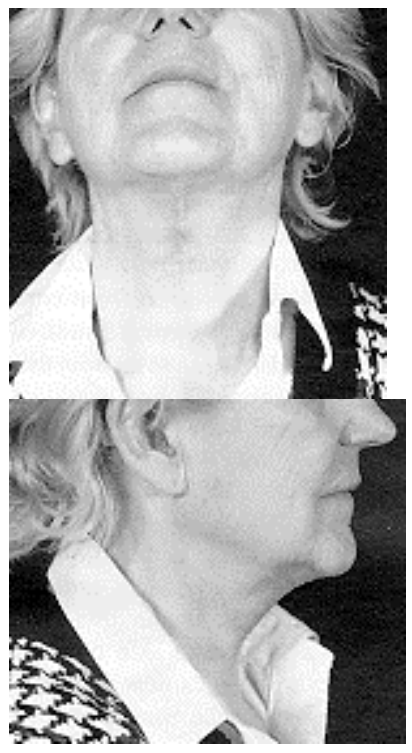

Figure 1F, 1G)

Diminished one year after intralesional steroids only, but worst results obtained in this series 
TABLE 1: Results of direct neck skin excision

\section{Minimal scar Thick scar Vertical shortening*}

Male

4

Female

Age over 653

Total

6

0

0

*Resulting in scar contracture

\section{RESULTS}

All patients readily tolerated direct neck skin excision in an office setting using only local anaesthesia without even intravenous sedation. No wound healing complications occurred except in one case of cellulitis treated with oral antibiotics in a patient who ultimately developed significant vertical banding (Figure 1E).

On close inspection of the neck, a scar was obvious in all patients which must be accepted as an inevitable sequela of this procedure (Table 1). Usually relatively inconspicuous, this was considered a minimal scar giving a good result in $75 \%$ of cases (Figures 2 and 3). All the men, all over 65 years old, obtained such a reasonable final appearance (Figure 2).
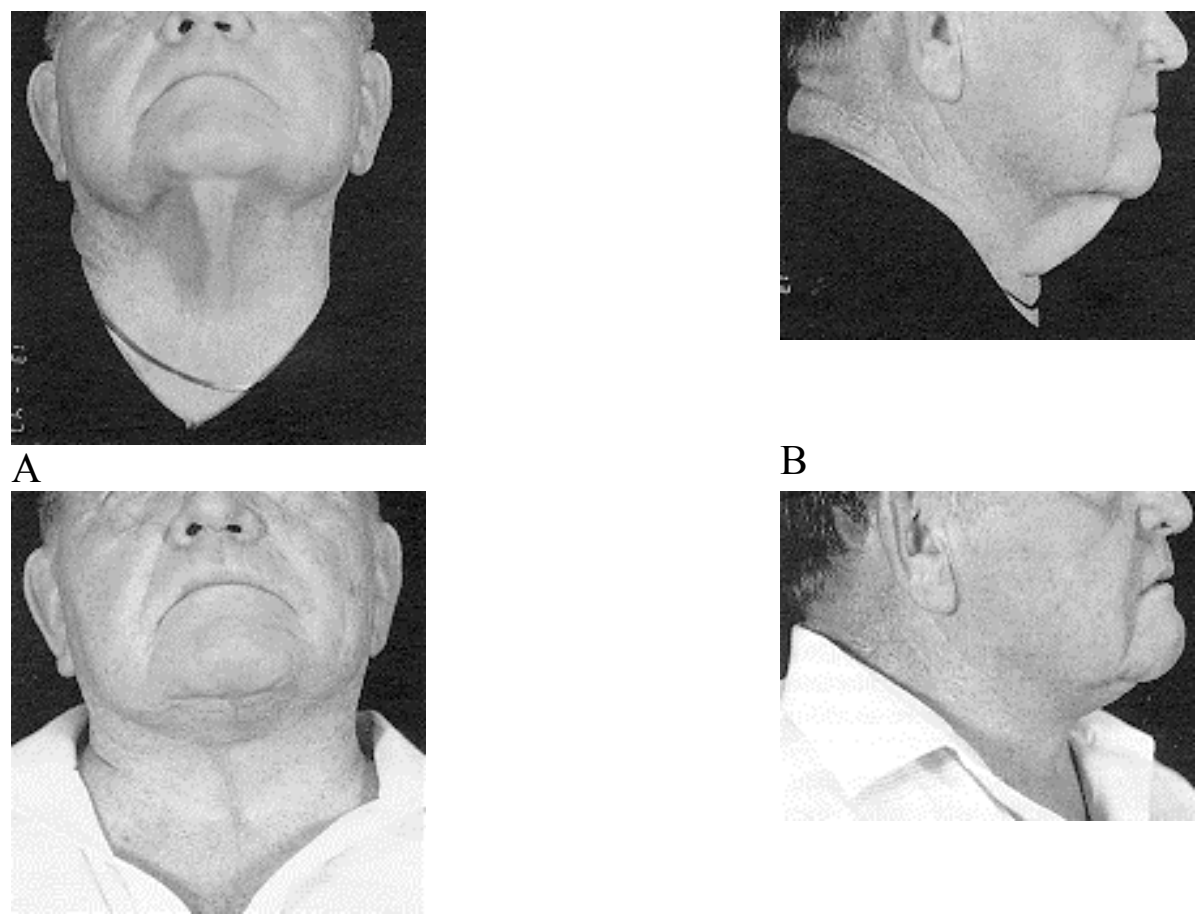

B

$\mathrm{C}$

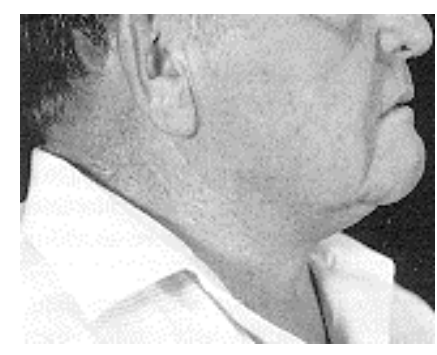

$\mathrm{D}$

Figure 2) $(A, B)$ Elderly male before, and $(C, D)$ six months following direct neck excision of wattle which satisfied his expectations 


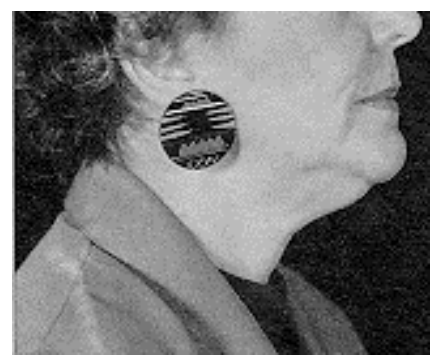

Figure 3A) Younger female who refused mentopexy and facelift, insisting on having submental neck enhancement

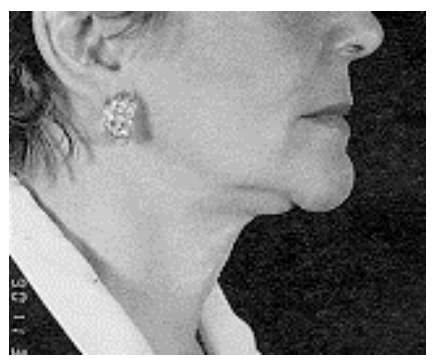

Figure 3B) Improved in this regard at 17 months

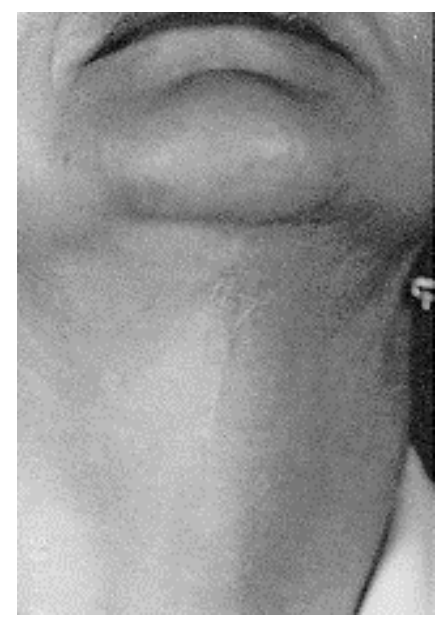

Figure 3C) however, on close-up examination she had obvious stigmata of scar from direct neck skin excision and Z-plasty

One woman developed a thick vertical scar causing a contracture which responded well to intralesional steroids (Figure 1E).

Another thick scar was revised by direct excision with incorporation of a second Z-plasty. Neither of these two cases could be considered even a satisfactory result.

\section{DISCUSSION}

According to Regnault and Daniel, surgical alterations to create the ideal neck must consider modification of multiple factors (11):

- position of the hyoid bone

- degree and location of neck adiposity

- platysmal borders and bands

- degree of chin projection

- jowl formation.

All these points are best corrected by treatment of the face and neck in unison (9), using any standard cervicofacial rhytidectomy technique (6-8). Many have condemned localized procedures alone for improvement of neck aesthetics $(9,11)$. Any visible scar is a great deterrent for any presently known method of direct neck skin excision (12). Since anatomically a relative deficit of vertical neck skin compared to the horizontal dimension exists in the preoperative deformity of this patient type (2), vertical contracture from excessive vertical skin excision may be an additional risk (Figure 1E).

Because of these inherent disadvantages, some surgeons reserve direct neck excisions only for men who refuse rhytidectomy (2-4). Women are better corrected by the usual facelift where their resultant scars are superior to those of the typical male (2). In this small series all observed complications occurred only in females in spite of Z-plasty modification of a $\mathrm{V}$-excision necklift. Since this technique always produces a conspicuous scar, consideration of this alternative is not acceptable unless the patient is willing to accept such an outcome without reservation. 


\section{REFERENCES:}

1. Adamson JE, Horton CE, Crawford HH. The surgical correction of the 'turkey gobbler' deformity. Plast Reconstr Surg, 1964;34:598-605.

2. Cronin BF, Biggs TM. The T-Z-plasty for the male 'turkey gobbler' neck. Plast Reconstr Surg 1971;47:534-8.

3. Biggs TM. T-Z-plasty for the male 'turkey gobbler' neck. Plast Reconstr Surg 1980;65:238.

4. Biggs TM, Koplin L. Direct alternative for neck skin redundancy in males. Clin Plast Surg 1983;10:423-8.

5. Kesselring UK. Direct approach to the difficult anterior neck region. Aesth Plast Surg 1992;16:277-82.

6. Baker TJ, Gordon HL. Surgical rejuvenation of the face. St Louis: CV Mosby Co, 1986:127-9.

7. Connell BF. Neck contour deformities: the art, engineering, anatomic diagnosis, architectural planning, and aesthetics of surgical correction. Clin Plast Surg 1987;14:68392.

8. Straith RE, Botta SA. Male face lift in continuity with lower blepharoplasty. Aesth Plast Surg 1988;12:9-21.

9. Millard DR, Mullin WR, Ketch LL. Surgical correction of the fat neck. Annal Plast Surg 1983;10:371-85.

10. Feldman JJ. Corset platysmaplasty. Plast Reconstr Surg 1990;85:333-43.

11. Regnault P Daniel RK. Rhytidectomy. In: Regnault P, Daniel RK, eds, Aesthetic Plastic Surgery, Boston: Little, Brown 1984:371-419.

12. de Castro CC. Preauricaular and sideburns operating procedures for a natural look in facelifts. Aesth Plast Surg 1991;15:149-53. 